\section{Anisakid nematodes as possible markers to trace fish products}

\author{
Vincenzo Ferrantelli, Antonella Costa, \\ Stefania Graci, Maria Drusilla Buscemi, \\ Giuseppe Giangrosso, \\ Claudia Porcarello, Silvia Palumbo, \\ Gaetano Cammilleri
}

National Reference Center for Anisakiasis - C.Re.N.A, Institute for Experimental Veterinary Medicine of Sicily A. Mirri, Palermo, Italy

\section{Abstract}

In this work a total of 949 fish samples were analysed for the identification of nematode larvae belonging to the Anisakidae family. Biomolecular application for the identification of Anisakidae larvae can be an optimal instrument for the traceability of fish products, described on the Reg. EC 178/2002. Results confirm a correlation between geographical distribution of fishes and presence of specific Anisakid larvae. FA0 37 zone (Mediterranean sea) showed a prevailing distribution of Anisakis pegreffii and a minimal presence of $A$. simplex s.s. in hybrid form with Anisakis pegreffii. FA0 27 zone showed a prevailing distribution of $A$. simplex s.s. in fish like Brosme (Brosme brosme) and infestation prevalence of Pseudoterranova krabbei and $P$. decipiens s.s. in Gadus morhua. Obtained results validate the hypothesis that molecular biology methods for identifying Anisakidae larvae are effective traceability markers of fish products.

\section{Introduction}

The Regulation (EC) n.178/2002 of 28 January 2002 (European Commission, 2002) defines the term traceability as the ability to trace and follow the path of a food-producing animals through all stages of production, processing and distribution. The food sector operators must have systems and procedures that allow the competent authorities to access information on the product in order to guarantee its traceability. Food commercialised in the European Community must therefore be labelled or identified to facilitate their traceability through relevant documentation or information describing geographical origin of the species, as in the case of fish products. Reg. (EC) 2065/2001 (European Commission, 2001) described and listed the fishing areas, following the division implemented by the
Food and Agriculture Organization (FAO). Despite these restrictions, consumers can bump into fraudulent suppliers who compromise the veracity of a product. Molecular biology methods, in this case, are a valuable tool in geographical identification of fish stocks. These methods exploit the principles of phylogeography, based on the alignment of DNA sequences obtained from fish and their genetic distance. A precise parassitofauna corresponds to a fish species present in a given area. Co-phylogeny is defined as the set of phylogenetic studies on parasites and their guests. Co-phylogenetic mapping is constructed to provide the best explanation of the phylogeny and to check if parasites have suffered genetic divergence with their guests. Recent studies have shown that phylogeny of the parasites tends to reflect that of the infested fish (Desdevises, 2007; Mattiucci et al., 2008). Hence, we can assume that parasites could be viewed as reliable markers for the traceability of fish products.

The need to use parasites as markers of fish traceability can be largely met by Anisakidae family. In this family of nematodes one can find parasites widely distributed throughout the globe. Anisakis pegreffii is the Anisakidae most present in the Mediterranean (Mattiucci et al., 2004), while Pseudoterranova is most frequent in North-East Atlantic (Desportes and McClelland, 2001). The aim of this study was to verify the correspondence between the parassitofauna of examined fishes and their geographical distribution, through molecular biology methods in order to promote a new methodology in traceability of fish products.

\section{Materials snd Methods}

\section{Sampling area and methodology}

Sampling areas belong to the North-East side of the Atlantic (FAO 27) and to the entire Mediterranean basin (FAO 37). Samplings were carried out from January 2013 to March 2014 within the Monitoring Regional Plan (monitoring plan for the search of Anisakidae larvae in fish products commercialised in Sicily) and as a consequence of research samplings. They were carried out by the veterinary in charge throughout the national territory, preferring products just fished. For each sample species and origin as described on the label (in imported products) and from reports of fishermen were registered (Table 1). Thirteen species of fish were sampled for a total of 949 samples. Samples were stored at 4 and $-20^{\circ} \mathrm{C}$ and analysed by the laboratories of the National Reference Center for Anisakiasis (C.Re.N.A). At first, samples underwent a visual examination for the research of parasites belonging to the family Anisakidae (Figure 1).
Correspondence: Vincenzo Ferrantelli, National Reference Center for Anisakiasis - C.Re.N.A, Institute for Experimental Veterinary Medicine of Sicily A. Mirri, via G. Marinuzzi 3, 90129 Palermo, Italy.

Tel: +39.091.6565255 - Fax: +39.091 .6565234 .

E-mail: vincenzo.ferrantelli@izssicilia.it

Key words: Fish traceability, Nematodes, Anisakidae, Molecular biology.

Received for publication: 19 May 2014.

Revision received: 15 October 2014.

Accepted for publication: 20 November 2014.

This work is licensed under a Creative Commons Attribution 3.0 License (by-nc 3.0).

(C) Copyright V. Ferrantelli et al., 2015

Licensee PAGEPress, Italy

Italian Journal of Food Safety 2015; 4:4090

doi:10.4081/ijfs.2015.4090

\section{Anisakidae parasites research and} identification of morphological characters

Fish samples were sectioned into a caudocranial sense and open for the detection of parasites by visual inspection. Parasites were inspectioned by a stereo-microscope (Zeiss CL 1500 EC0; Zeiss, Oberkochen, Germany). Detected larvae were preserved in 70\% ethanol for $24 \mathrm{~h}$ and subjected to identification of morphological characters. Genre identification has been carried out by optical microscopy (Leica DM 3000; Leica, Wetzlar, Germany) on parasite samples clarified in glycerol. Morphological characters able enough to discriminate the genre of the larvae and the morfotype of genus Anisakis were analysed.

\section{Anisakidae species object of the study}

Anisakis and Pseudoterranova were the parasites genera considered by this study due to their geographical correlation with the sampling areas (Mattiucci et al., 2008). Anisakis larvae are divided into morphotype I and II. Morphotype I have parasites more distributed in Mediterranean. Anisakis pegreffii is the most detectable Anisakidae species in Mediterranean fish with a prevalence of infestation in scabbard fish (Lepidopus caudatus), anchovy (Engraulis encrasicolus), horse mackerel (Trachurus trachurus), and sardines (Sardina pilchardus). A. simplex s.s. also belongs to morphotype I and it is a parasite species that infestis in greater measure fish belonging to North-East Atlantic (Portuguese coast, North Sea). P. decipiens s.s. and $P$. krabbei are species of Pseudoterranova which can be found in North-East Atlantic fish (Costa et al., 2013). P. decipiens s.s. extends in a range 
of distribution including the North-East Atlantic (Scotland, Faroe Islands, Norway, etc.) and the Canadian Atlantic (Brattey and Stenson, 1993; Paggi et al., 1991). There are simpatry areas with species of the same complex (Pseudoterranova decipiens complex) as $P$. krabbei in North-East Atlantic, where it can be found in co-infestation in the same fish. Larval forms of $P$. decipiens s.s. are mostly present in cod of the North Atlantic (Mattiucci et al., 1998; Desportes and McClelland, 2001). P. krabbei is a parasite found in the NorthEastern side of the Atlantic; its larval form infests Osteichthyes such as the Atlantic cod (Gadus morhua) and the black cod (Pollachius virens) (Paggi et al., 1991).

\section{Molecular analysis}

Larval samples previously preserved in ethanol (70\%) were rehydrated with sterile water, fragmented with a scalpel, placed in an eppendorf with $200 \mathrm{~L}$ of nuclease free water and frozen at $-20^{\circ} \mathrm{C}$ for $24 \mathrm{~h}$.

\section{DNA extraction}

For DNA extraction special kits based on affinity principle pedestals were used (Sigma Aldrich, St. Louis, M0, USA). The concentration of extracted DNA was assessed by spectrophotometric method at $260 \mathrm{~nm}$. The solution containing DNA was stored at $-20^{\circ} \mathrm{C}$, in order to avoid repeated freezing and thawing which may interfere with the amplification reaction [polymerase chain reaction (PCR)].

\section{DNA amplification}

Polymerase chain reaction was divided into 3 phases. First, preparation of a master mix in reaction tubes with anhydrous reagents, in a water and primers NC5 (5'-GTA GGT GAA CCT GCG GAA GGA TCA TT-3') and NC2 (5'-TTA GTT TCT TTT CCT CCG CT-3') mix. NC5 and NC2 are primers that amplify the nuclear rDNA region (ITS1-5.8S-ITS2). Final volume was 25 mL. Subsequently, samples were transferred into a Termal Cycler (2720 Applied Biosystems; Applied Biosystems, Carlsbad, CA, USA) and subjected to the following PCR condition: $95^{\circ} \mathrm{C}$ for $10 \mathrm{~min} ; 35$ cycles of $30 \mathrm{~s}$ at $95^{\circ} \mathrm{C}, 30 \mathrm{~s}$ at $58^{\circ} \mathrm{C}$, and $1,5 \mathrm{~min}$ at $72^{\circ} \mathrm{C}$; final polymerisation at $72^{\circ} \mathrm{C}$ for $15 \mathrm{~min}$. Amplification products were finally detected by agarose gel elec-

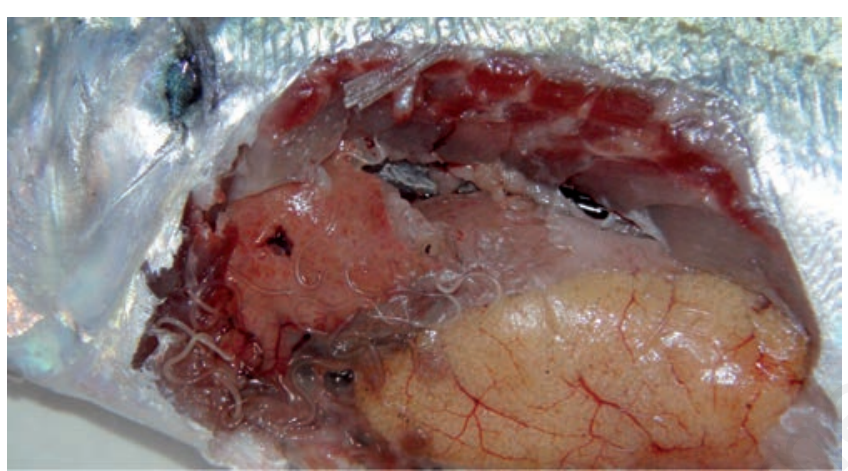

Figure 1. Visual inspection of Trachurus trachurus viscera for the detection of parasites.

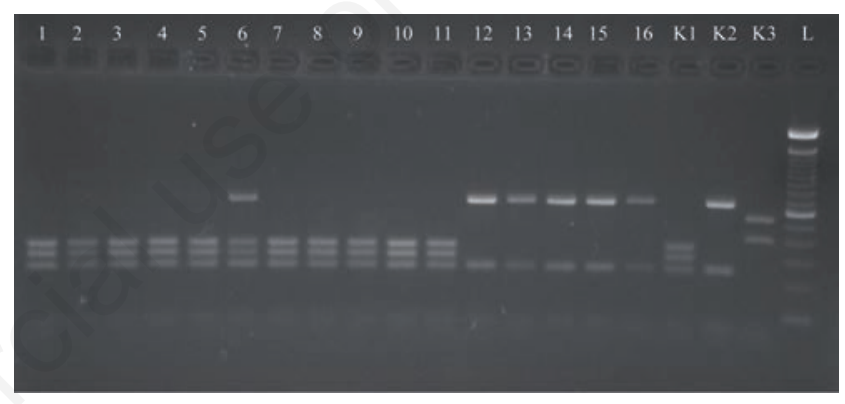

Figure 2. Restriction pattern with Hinf I. Lanes 1 to 5 and 7 to $11=$ Anisakis pegreffii; lane 12 to $16=$ Anisakis simplex s.s.; lane 6=A. pegreffi/A. simplex s.s.; K1=positive control $A$. pegreffii; K2=positive control $A$. simplex s.s.; K3=positive control $A$. physeteris; $\mathrm{L}=$ ladder.

Table 1. Analysed samples divided by fish species and fishing area.

\begin{tabular}{|c|c|c|c|c|c|c|c|}
\hline Type of sample & Scientific name & FAO 37.1.3 & FAO 37.1.1 & FAO 37.2.2 & $\begin{array}{c}\text { Fishing area } \\
\text { FAO } 27 \\
\text { (subarea IXa) }\end{array}$ & $\begin{array}{c}\text { FAO } 27 \\
\text { (subarea IV;V) }\end{array}$ & Total \\
\hline Anchovy & Engraulis encrasicolus & 117 & 107 & 46 & 0 & 0 & 270 \\
\hline Brosme & Brosme brosme & 0 & 0 & 0 & 0 & 4 & 4 \\
\hline Tub gurnard & Chelidonychtis lucernus & 0 & 0 & 0 & 0 & 6 & 6 \\
\hline Conger & Conger conger & 0 & 0 & 2 & 0 & 0 & 2 \\
\hline Hake & Merluccius merluccius & 48 & 0 & 8 & 0 & 0 & 56 \\
\hline Atlantic Cod & Gadus morhua & 0 & 0 & 0 & 0 & 3 & 3 \\
\hline Scabbard fish & Lepidopus caudatus & 2 & 0 & 2 & 0 & 0 & 4 \\
\hline Monkfish & Lophius piscatorius & 3 & 0 & 0 & 0 & 0 & 3 \\
\hline Sardine & Sardina pilchardus & 178 & 0 & 284 & 0 & 0 & 462 \\
\hline Redfish & Scorpaena scrofa & 11 & 0 & 0 & 0 & 0 & 11 \\
\hline Mackerel & Scomber scombrus & 10 & 0 & 9 & 8 & 0 & 27 \\
\hline Horse Mackerel & Trachurus trachurus & 40 & 10 & 15 & 15 & 0 & 80 \\
\hline Squid & Todarodes sagittatus & 17 & 0 & 4 & 0 & 0 & 21 \\
\hline Total of samples & & & & & & & 949 \\
\hline
\end{tabular}


trophoresis (1\%) and subjected to restriction fragment length polymorphism (RFLP).

\section{Polymerase chain reaction-restric-} tion fragment length polymorphism

The restriction was performed by the use of two different restriction enzymes (HhaI and HinfI) with the following sequences: HhaI:GCG C - CGC G; HinfI: GANTC - CTNA G. Each sample reached a final volume of $20 \mu \mathrm{L}$. Digestion of amplicons was performed by incubation at $37^{\circ} \mathrm{C}$ O.N. Detection of the digestion products was carried out by electrophoresis in agarose gel ( $2 \%$ ). Restriction fragment length polymorphism data, analysed by electrophoresis, reveal the restriction patterns relating to the different species of Anisakis, according to the interpretation key (D'Amelio et al., 2000; Pontes et al., 2005). Results were interpreted by evaluation of obtained restriction profiles for comparison with the molecular weights marker and positive control (Figure 2). The interpretation of restriction profiles belonging to A. pegreffiA. simplex s.s. hybrid refers to the work of Abollo et al. (2003).

\section{Pseudoterranova DNA sequencing}

Pseudoterranova identification cannot be executed by PCR-RFLP due to restriction pattern absence, so it was conducted a mitochondrial DNA sequencing. cox2 mithocondrial region was amplified by the use of primers 210 (5'CACCAACTCTTAAAATTATC-3') and 211 (5'TTTTCTAGTTATATAGATTGRTTYAT-3') (20 $\mathrm{pmol} / \mu \mathrm{L}$ ) with $R N A s i$ and $D N A s i$-free water, buffer $1 \mathrm{x}, \mathrm{MgCl}_{2} 2 \mathrm{mM}$, DNTPs $0.2 \mathrm{mM}$, Taq gold polymerase $(6 \mathrm{U})$ and 10-20 ng of DNA, in a final volume of $50 \mathrm{~L}$. The following PCR condition was set: $8 \mathrm{~min}$ at $95^{\circ} \mathrm{C}, 35$ cycles of $50 \mathrm{~s}$ at $95^{\circ} \mathrm{C}, 1 \mathrm{~min}$ at $52^{\circ} \mathrm{C}, 1 \mathrm{~min}$ at $72^{\circ} \mathrm{C}$ and a final extension of $72^{\circ} \mathrm{C}$ for $7 \mathrm{~min}$ (Termal Cycler 2720 Applied Biosystems). Polymerase chain reaction products (629 bp fragments), were visualised by electrophoresis on $1.5 \%$ agarose gel with Syber Safe DNA Gel Stain (Invitrogen, Carlsbad, CA, USA). Amplified fragments were purified by GFX Microspin columns and undergo to sequence reaction by Big Dye Terminator Cycle Sequencing kit (Applied Biosystems). The sequence products were purified by $\mathbf{G 5 0}$ columns (GE), denatured and analysed with capillary electrophoresis on automated sequencer 3130 Biotec 69 . Obtained sequences were aligned with the most similar sequences available in GenBank using the Nucleotide BLAST software (Mattiucci et al., 2010; Nadler and Hudspeth, 2000).

\section{Results}

Figure 3 shows the values of infestation prevalence for examined species (expressed as a percentage). Obtained results were normalised by the indication of examined samples for species. Infestation prevalence of the most sampled species (sardines, anchovies, mackerel, nibs) is similar to the one published by other authors (Mattiucci et al. 2004). Molecular analysis was carried out on 329 larval samples. For each fish sample a statistically significant number of larvae $(\approx 10 \%)$ was examined: 207 belonging to $A$. pegreffii, 64 to A. simplex s.s., 3 to A. physeteris and 17 to $A$. pegreffii/simplex s.s. hybrid form, as described by Abollo et al. (2003). Sequencing technique placed Pseudoterranova larvae as $P$. krabbei (Sequence ID: HM147279) for 36 samples and
P. decipiens s.s. for 2 (Sequence ID: HM147278.1) (Figure 4). Geographical division showed A. simplex s.s., P. krabbei, P. decipiens s.s. belonging to the FAO 27 zone, while $A$. pegreffii, A. physeteris and A. simplex s.s. species belonging to FAO 37 zone (Figure 5). Obtained results show a species-specific prevalence of host for mackerel and brosme, infested by $A$. simplex s.s. Furthermore, an infestation difference between Atlantic and Mediterranean mackerel has been highlighted: Atlantic mackerel were an infestation by $A$. simplex s.s. larvae, while Mediterranean mackerel showed a prevalence of $A$. pegreffii infestation. A. simplex s.s. proved to be present both in

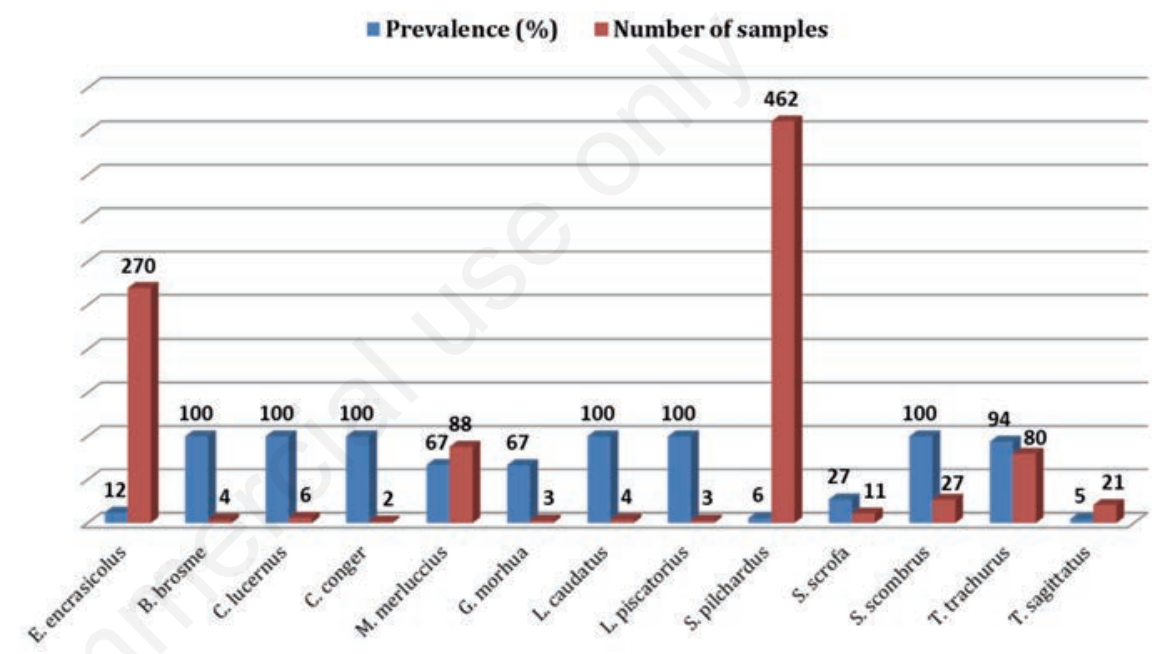

Figure 3. Infestation prevalence of Anisakidae family larvae according to analysed fish species.

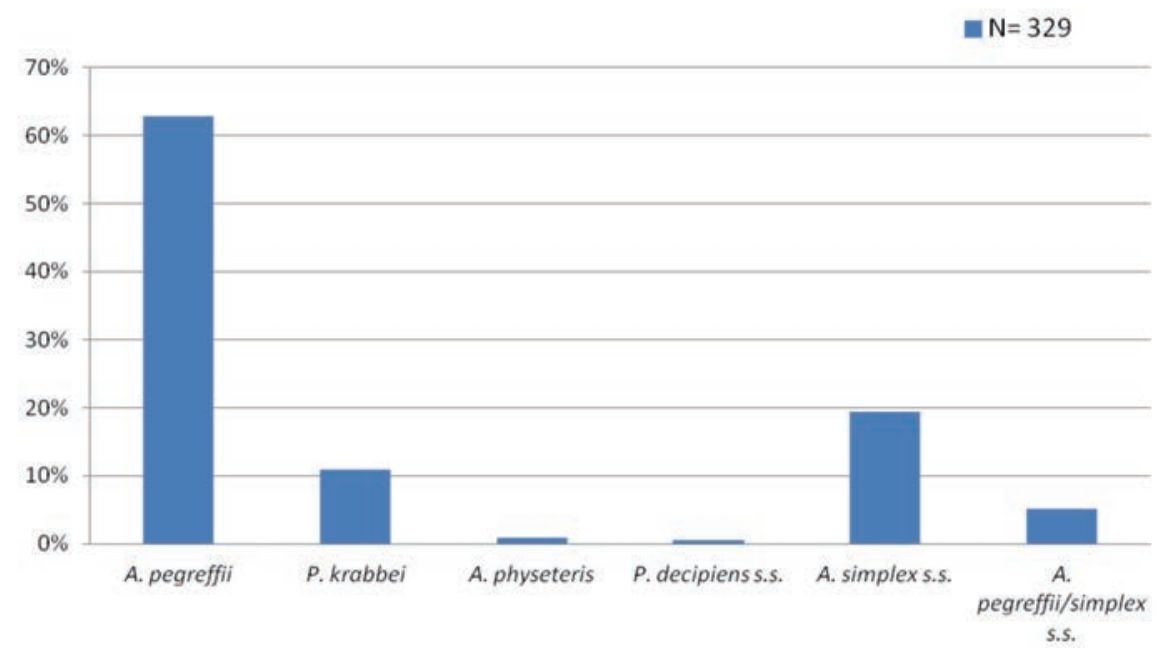

Figure 4. Prevalece of analysed Anisakidae larve (\%). 
2003), such as mackerel in the Mediterranean.

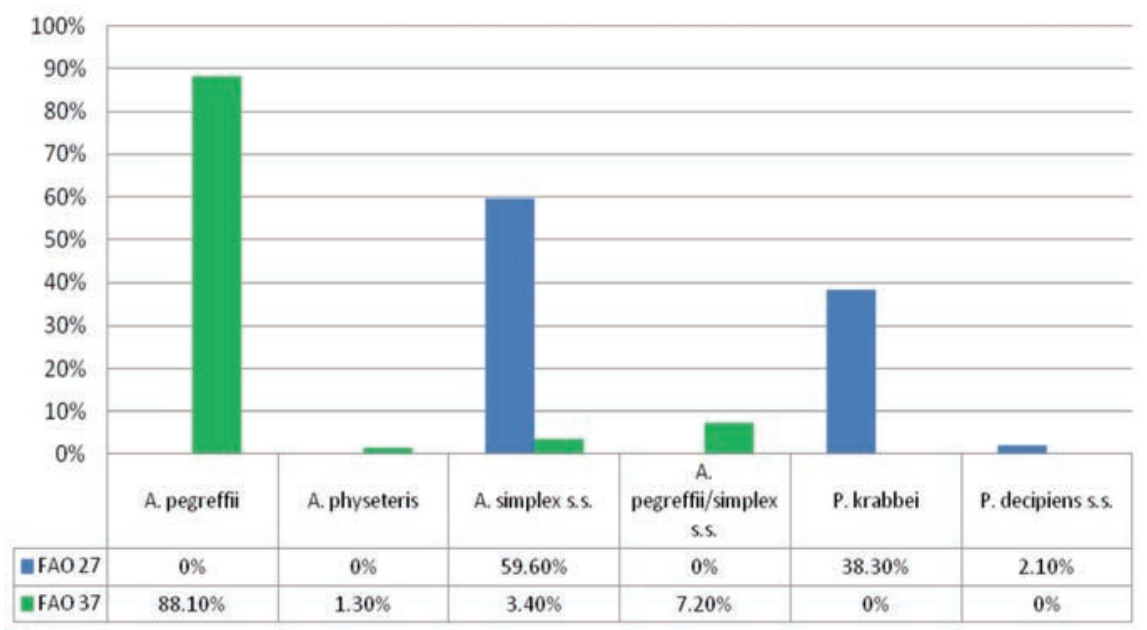

Figure 5. Anisakidae larvae prevalence according to FAO zone.

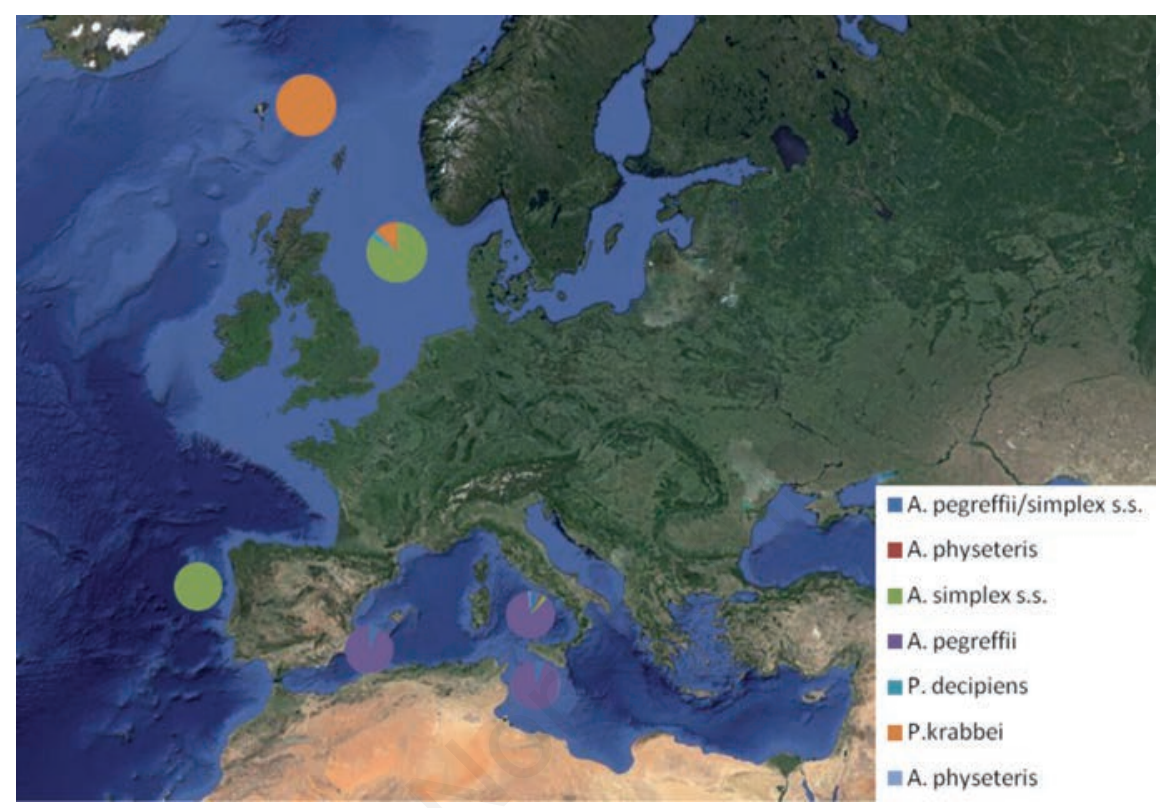

Figure 6. Infestation prevalence of Anisakidae larvae according to sampling area.

the North-Eastern Atlantic and in the Mediterranean, where it was found as hybrid form with $A$. pegreffii just as described by Mattiucci et al. (2008). Figure 5 evidences a greater presence of A. simplex s.s. on FAO 27 zone.

\section{Discussion}

Results showed a marked geographical breakdown of the larvae belonging to the family Anisakidae (Figure 6). This study confirmed the endemism and prevalence of $A$. pegreffii in FAO 37 zone, as demonstrated in previous work (Mattiucci et al., 2008), while FA0 27 zone shows the presence of two Pseudoterranova species and one of Anisakis (A. simplex s.s.). In the Mediterranean area $A$. simplex s.s. mostly comes in the hybrid form with the autochthonous species A. pegreffii. This hybridisation could derive from the movement of migratory fish banks (Abollo et al.,
Obtained results in mackerel (Scomber scombrus) prove this hypothesis. In the Mediterranean, the presence of $A$. pegreffiv $A$. simplex s.s. hybrids and A. simplex s.s. was most detected in FAO sub-areas 37.1.1 and 37.1.3 (htpp://www.FA0.org/fishery/area/ Area37/en). These 2 fishing areas are very close to the Gibraltar strait and then to the Atlantic seaboard. A confirmation of the distribution specificity of the Anisakidae larvae was also due to the presence of two different Anisakis species in Trachurus trachurus (horse mackerel). In the Mediterranean horse mackerel (FAO area 37) it was found only the presence of $A$. pegreffii, while in North-East Atlantic horse mackerel only A. simplex s.s. larvae were discovered. This study confirmed a co-evolution hypothesis between parasite and its host.

\section{Conclusions}

In conclusion, it is possible to consider Anisakid nematodes as a marker of fish traceability. The application of biomolecular methods for the identification of Anisakidae larvae could be an additional tool for the confirmation of fish product origin and a valid anti-fraud methodology for the protection of EC Reg.178 $/ 2002$.

\section{References}

Abollo E, Paggi L, Pascual S, D’Amelio S, 2003. Occurrence of recombinant genotypes of Anisakis simplex s.s. and Anisakis pegreffii (Nematoda: Anisakidae) in an area of sympatry. Infect Genet Evol 3:175-81.

Brattey J, Stenson GB, 1993. Host specificity and abundance of parasitic nematodes (Ascaridoidea) from the stomachs of five phocid species from Newfoundland and Labrador. Can J Zool 71:2156-66.

Costa A, Palumbo P, Graci S, Cammilleri G, Fischetti R, Marconi P, Ferrantelli V, 2013. Larve di anisakidae isolate da prodotti ittici d'importazione: identificazione morfologica e molecolare. In: Caracappa S, Lelli R, Montanari G, eds. Proceedings of the 15th S.I.Di.L.V. National Congress, 2013 0ct 2325, Monreale, Italy. Italian Society of Veterinary Laboratory Diagnostics, Parma, Italy, pp 204-206.

D’Amelio S, Mathiopoulos KD, Santos CP, Pugachev ON, Webb SC, Picanço M, Paggi L, 2000. Genetic markers in ribosomal DNA for the identification of members of thegenus Anisakis (Nematoda:Ascaridoide a) defined by polymerase-chain-reactionbased restriction fragment length polymorphism. Int J Parasitol 30:223-6. 
Desdevises Y, 2007. Cophylogeny: insights from fish-parasite systems. Parassitologia 49:125-8.

Desportes G, McClelland G, 2001. Sealworms in the North Atlantic: ecology and population dynamics. NAMMCO Publ., Troms $ø$, Norway.

European Commission, 2001. Regulation of the European Parliament of 22 October 2001 laying down detailed rules for the application of Council Regulation (EC) No $104 / 2000$ as regards informing consumers about fishery and aquaculture products, 2065/2001/EC. In: Official Journal, L 278/6, 23/10/2001.

European Commission, 2002. Regulation of the European Parliament and of the Council of 28 January 2002 laying down the general principles and requirements of food law, establishing the European Food Safety Authority and laying down procedures in matters of food safety, 178/2002/EC. In: Official Journal, L 31/1, 01/02/2002.
Mattiucci S, Abaunza P, Ramadori L, Nascetti G, 2004. Genetic identification of Anisakis larvae in European hake from Atlantic and Mediterranean waters for stock recognition. J Fish Biol 65:495-510.

Mattiucci S, Farina V, Campbell N, MacKenzie K, Ramos P, Pinto AL, Abaunza P, Nascetti G, 2008. Anisakis spp. larvae (Nematoda: Anisakidae) from Atlantic horse macere: their genetic identification and use as biological tags for host stock characterization. Fish Res 89:146-51.

Mattiucci S, Paggi L, Nascetti G, Ishikura H, Kikuchi K, Sato N, Cianchi R, Bullini L, 1998. Allozyme and morphological identification of Anisakis, Contracaecum and Pseudoterranova from Japanese waters (Nematoda: Ascaridoidea). Syst Parasitol 40:81-92.

Mattiucci S, Paoletti M, Nascetti G, 2010. Pseudoterranova and Contracaecum. In: Mattiucci S, Paoletti M, Webb SC, and Nascetti G, eds. Molecular detection of human parasitic pathogens. CRC Press, Boca Raton, FL, USA, pp 645-56.

Nadler SA, Hudspeth DSS, 2000. Phylogeny of the Ascaridoidea (Nematoda: Ascaridida) based on the genes and morphology: hypotheses of structural and sequence evolution. J Parasitol 86:380-93.

Paggi L, Nascetti G, Cianchi R, Orecchia P, Mattiucci S, D’Amelio S, Berland B, Brattey J, Smith JW, Bullini L, 1991. Genetic evidence for three species within Pseudoterranova decipiens (Nematoda, Ascaridida, Ascaridoidea) in the North Atlantic and Norwegian and Barents Seas. Int J Parasitol 21:195-212.

Pontes T, D’Amelio S, Costa G, Paggi L, 2005. Molecular characterization of larval Anisakid nematodes from marine fishes of Madeira by a PCR-based approach, with evidence for a new species. J Parasitol 91:1430-4. 